\title{
Is the Bose 901 Direct Reflecting Speaker an Educational Tool?
}

\author{
By Brian Szymanski
}

$\mathbf{T}$ he Bose 901 Direct Reflecting speaker system has been a legendary flagship speaker for the Bose Corporation since it was introduced 1968. This speaker has also influenced other Bose product lineups. Currently, the Bose Corporation is committed to developing an uncompromising commitment to lifelike sound and the company logo is Better Sound through Research which stemmed from the 901's success (Bose 901, 2010).

In 1964 Dr. Amar Bose, a professor at that time within the electrical engineering department at the Massachusetts Institute of Technology (M.I.T.), founded the Bose Corporation (Bose, 2010). His passion for speakers developed while he was a graduate student at M.I.T. after purchasing a high end audio system that he felt lacked depth and lifelike sound (Lemley, 2004). This incident was one of the prime motivating factors that contributed to the design and advancement of the Bose 901, the first product developed and produced by Dr. Bose and the basis for all future speakers produced by his company.

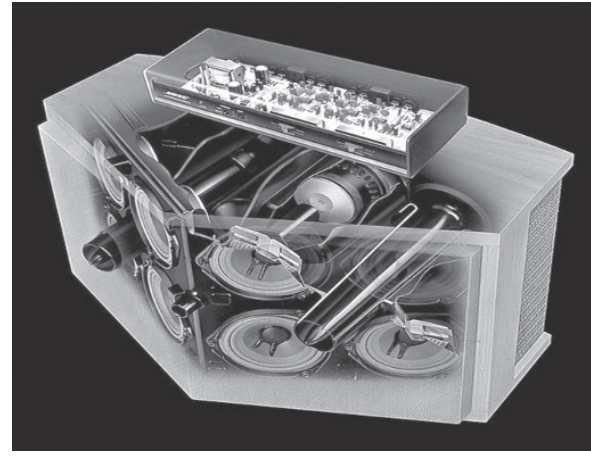

Figute 1. Smarthome, 2010

Bose's concept of reflected and direct sound, modeled after concert hall acoustics, won the respect of expert and novice audiophiles alike and paved the way for future successes and new advancements within the audio field. Although the Bose 901 was not invented for a classroom setting, this speaker has lent itself along with other Bose products, to many K-12 and higher education auditoriums, hotels, restaurants, and places of worship in providing superior sound for voice and music. Even the Sistine Chapel contains Bose speakers.

The Bose 901 is designed to directly reflect $89 \%$ of the sound from the rear of the speaker and the remaining $11 \%$ from the front by way of nine total speakers (Holt, 1979). This configuration proportion was discovered by a Bose-Directed MIT research team which studied various halls where live performances were featured (Bose, 2010). This unique design created a worldwide revolution in speaker systems for home, business, automotive, aviation, and more.

\section{References}

Bose Website. (2010). "Home stereo speakers: 901 direct reflecting speaker system."

Retrieved from: http://www.bose.com/ controller?url=/shop_online/speakers/

stereo_speakers/901_speakers/index.jsp.

Holt, Gordon. J. (1979). "Audiophile: Review of Bose 901s.” Retrieved from:

http://www.stereophile.com/standloudspeakers $/ 425 /$.

Lemley, Brad. (2004). "Discover dialogue: Amar G. Bose." Retrieved from:

http://discovermagazine.com/2004/oct/discover-dialogue.

Smarthome Website. (2010). “Bose 901 Direct reflecting speaker.” Retrieved

from: http://www.smarthome.com/ images/972493sidelbig.jpg. 